\title{
Correlation of Gerkin, Queen's College, George, and Jackson methods in estimating maximal oxygen consumption
}

\author{
Payam Heydari ${ }^{1}$, Sakineh Varmazyar ${ }^{2}$, Ali Safari Variani ${ }^{3}$, Fariba Hashemi ${ }^{4}$, Seyed Sajad Ataei ${ }^{5}$
}

\begin{abstract}
${ }^{1}$ M.Sc. of Occupational Health Engineering. Department of Occupational Health Engineering, Social Determinants Health Research Center, Faculty of Health, Qazvin University of Medical Sciences, Qazvin, Iran

${ }^{2} \mathrm{Ph} . D$. of Occupational Health Engineering. Assistant Professor, Department of Occupational Health Engineering, Social Determinants Health Research Center, Faculty of Health, Qazvin University of Medical Sciences, Qazvin, Iran

${ }^{3}$ Ph.D. of Occupational Health Engineering. Associate Professor, Department of Occupational Health Engineering, Qazvin University of Medical Sciences, Qazvin, Iran

${ }^{4}$ M.Sc. of Operating Room. Lecturer, Department of Operating Room, Faculty of Paramedical, Qazvin University of Medical Sciences, Qazvin, Iran

${ }^{5}$ Expert of Occupational Health Engineering
\end{abstract}

\section{Type of article: Original}

\begin{abstract}
Background and aim: Test of maximal oxygen consumption is the gold standard for measuring cardiopulmonary fitness. This study aimed to determine correlation of Gerkin, Queen's College, George, and Jackson methods in estimating maximal oxygen consumption, and demographic factors affecting maximal oxygen consumption.

Methods: This descriptive cross-sectional study was conducted in a census of medical emergency students $(\mathrm{n}=57)$ in Qazvin University of Medical Sciences in 2016. The subjects firstly completed the General Health Questionnaire (PAR-Q) and demographic characteristics. Then eligible subjects were assessed using exercise tests of Gerkin treadmill, Queen's College steps and non-exercise George, and Jackson. Data analysis was carried out using independent t-test, one way analysis of variance and Pearson correlation in the SPSS software.

Results: The mean age of participants was $21.69 \pm 4.99$ years. The mean of maximal oxygen consumption using Gerkin, Queen's College, George, and Jackson tests was 4.17, 3.36, 3.64, 3.63 liters per minute, respectively. Pearson statistical test showed a significant correlation among fours tests. George and Jackson tests had the greatest correlation $(\mathrm{r}=0.85, \mathrm{p}>0.001)$. Results of tests of one-way analysis of variance and $\mathrm{t}$-test showed a significant relationship between independent variable of weight and height in four tests, and dependent variable of maximal oxygen consumption. Also, there was a significant relationship between variable of body mass index in two tests of Gerkin and Queen's College and variable of exercise hours per week with the George and Jackson tests $(\mathrm{p}>0.001)$.

Conclusion: Given the obtained correlation, these tests have the potential to replace each other as necessary, so that the non-exercise Jackson test can be used instead of the Gerkin test.

Keywords: Maximal oxygen consumption, Gerkin, Queen's College, George, Jackson, Medical emergency
\end{abstract}

\section{Introduction}

Awareness of appropriate function of the cardio-pulmonary system can be effective in health promotion planning. As people with cardio-pulmonary fitness and higher aerobic power can survive longer in hard work and fatigue. Therefore, a test of maximal oxygen consumption is the gold standard for measuring cardio-pulmonary fitness $(1,2)$. Maximal oxygen consumption is maximum power for consuming oxygen (liter per minute) during physical activity,

\section{Corresponding author:}

Assistant Professor Dr. Sakineh Vramazyar, Qazvin University of Medical Sciences, Qazvin, Iran.

Tel: +98.2833359502, Fax:+98.2833345865, Email: Svarmazyar@qums.ac.ir

Received: June 21, 2016, Accepted: June 27, 2017, Published: October 2017

iThenticate screening: October 27, 2016, English editing: September 09, 2017, Quality control: October 02, 2017

(C) 2017 The Authors. This is an open access article under the terms of the Creative Commons Attribution-NonCommercialNoDerivs License, which permits use and distribution in any medium, provided the original work is properly cited, the use is non-commercial and no modifications or adaptations are made. 
which depends on many factors including hereditary, age, gender and exercise. Maximal oxygen consumption can be measured in a lab, field or by a questionnaire (without activity). The lab method has a high accuracy and reliability. However, it is not always possible to assess aerobic fitness using a lab method due to lack of access to lab equipment, expensive equipment and not performing the lab test in any condition. Thus, researchers use field methods based on simple performance and being inexpensive, despite lower accuracy and reliability. On the other hand, some researchers are not able to use field methods due to inappropriate time and place and lack of cooperation. Therefore, non-activity tests were evaluated for assessment of aerobic power in individuals. Field tests can be referred as Gerkin treadmill and Queen's College step, and non-activity tests can be referred as George and Jackson tests. The Gerkin treadmill test was approved and evaluated by the National Society of Fire Protection in 1997. One of the main advantages of this test is its simplicity, without the need for advanced equipment, lower cost compared to direct measurement of maximal oxygen consumption and lower risk for people with heart disease (2, 3). Queen's College step test was designed by McArdel et al. in 1972, which estimates maximal oxygen consumption through reaction of heart rate in the refractory period. This method determines aerobic fitness and has less step height, slower pace, shorter and more simple analysis compared to other step tests such as Harvard. Advantages of this method are that there is less requirement for equipment, its cost, it is less time-consuming, and its self-administration (4-6). In 1990, Jackson et al. developed regression equation for a diverse sample of 2000 men and women. It can be used for calculating maximal oxygen consumption without an exercise test $(7,8)$. In 1997, George et al. developed a new regression equation which can calculate maximal oxygen consumption through variables of body mass index, score of physical activity and perceived practical ability. Target population of this test is male and female students 18 to 29 years with similar physical activity levels. Predicted accuracy of this equation is $\mathrm{R}=0.86, \mathrm{SEE}=3.34 \mathrm{ml} / \mathrm{kg} / \mathrm{min}$. The above-mentioned tests are assessed separately in many researches. No research directly assessed these four tests or estimated maximal oxygen consumption in medical emergency students. Also each test is carried out in different manners. Specific tools and equipment are required for conducting each test, and not all of them may be available. Therefore, investigating correlation of these tests can be used in order to replace these four tests in different conditions and places with different equipment. This study aimed to examine correlation of Gerkin, Queen's College and George, and in estimating maximal oxygen consumption.

\section{Material and Methods}

\subsection{Research design and sampling}

This descriptive cross-sectional study was conducted in a census of medical emergency students $(\mathrm{n}=57)$ in Qazvin University of Medical Sciences in 2016. Sample size was conducted through a census of medical emergency students who were eligible to be included in the study $(\mathrm{n}=59)$.

\subsection{Selection criteria}

The inclusion criteria were the following: no history of cardio-pulmonary or musculoskeletal diseases, not taking sedatives or pain relief medications, not working in a job with a high physical activity level. Physical activity readiness. If a participant reported one of the signs and symptoms of cardiovascular problems, he was classified into the high risk level and excluded from the study.

\subsection{Measurement Tool}

\subsubsection{Demographic characteristics Checklist}

This checklist consists of two parts. The first part was conducted through interviews with students, and the second part was completed through measuring required parameters by the researchers. The first part of the questionnaire includes questions about age, marital status, level of education, suffering from particular diseases, smoking, doing exercise, taking medications. The second part of the questionnaire includes variables such as height, weight, body mass index, heart rate (measured by a Beurer rate meter).

2.3.2. Questionnaire (PAR-Q):

It consists of questions about knowledge of general health. It was completed by individuals in order to verify their health. This questionnaire classifies risk of cardiovascular problems during exercise into three levels of low, moderate and high.

\subsubsection{Rating Perceived exertion (RPE)}

This questionnaire is used to determine the level of physical effort in participants. Individuals identify level of feeling during activity in a range from without effort (score 6) to greatest effort (score 20).

2.3.4. Gerkin Treadmill Test

Required equipment for performing the test is a heart rate monitor and chronometer. Firstly, an individual starts moving on the treadmill for 3 minutes with 3 miles per hour speed. After 3 minutes, the speed reaches to 4.5 miles 
per hour; the individual continues the activity at this speed. After 1 minute, 0.5 miles per hour is added to the speed and $2 \%$ to the slope. When the heart rate reaches to $85 \%$ of maximum heart rate, the treadmill stops and recovery hear rate is measured. The recovery heart rate is recorded in the end of a 3-minute cool down. Then maximal oxygen consumption is calculated using a formula (2).

2.3.5. Queen's College Step Test

Required equipment for performing this test include metronome, step in 16.25 in height or $41.3 \mathrm{~cm}$, a heart rate monitor and a chronometer. In this test, a metronome is set for men, at 22 steps per minute and for 3 minutes. Before the test, the heart rate in rest is recorded, and $85 \%$ of maximal heart rate is calculated. The participant received necessary teaching. The individual turns on the chronometer and starts the test. After 3 minutes, the heart rate is recorded 15 seconds after the end of the test. If an individual was not able to continue the test for any reason, the stop time is recorded, and the heart rate is recorded. Then, given the obtained heart rate after ending the test, maximal oxygen consumption can be calculated through a formula $(4,5)$.

2.3.6. Jackson non-Exercise Test

Estimation of maximum aerobic capacity using this test, depends on the score obtained in a simple questionnaire including history of exercise and parameters such as age, weight, height and gender. Thus, no exercise test is needed; however, a measurement of exercise history can be obtained using the questionnaire. Then, maximal oxygen consumption is calculated using a formula $(7,8)$.

2.3.7. George non-exercise Test

Estimation of maximum oxygen consumption using this test is similar to the Jackson no-exercise test. However, classification of activity level is broader in the George test and includes scales of perceived functional ability (score 2- 26) and rate of physical activity (score $0-10$ ). Maximal oxygen consumption is calculated using multiple regression (9).

\subsection{Data collection}

In order to ensure more accuracy in data collection, each stage of work was conducted by the same researcher until completion of sampling (completing questionnaire of general health and demographic characteristics, performing Gerkin and Queen's College tests, completing George and Jackson questionnaires). Students who met the inclusion criteria and general health were selected. After presenting necessary explanations, tests of Gerkin aerobic treadmill and Queen's College step were performed. Participants must avoid doing any exercise, eating food, taking agents affecting heart rate such as coffee, soft drinks, energetic pills and beverages, 24 hours before the test. Tests were performed over two days. On the first day, participants completed the general health questionnaire, demographic characteristics checklist and George and Jackson tests. Then, the step test was performed after two days.

\subsection{Ethical consideration}

This study was approved by the Research Ethics Committee in Qazvin University of Medical Sciences (IR.QUMS.REC.1395.40). The following measures were performed in order to prevent any physical and psychological harm to the participants:

- Considering the inclusion criteria for the participants

- Completing general health for the participants and excluding participants with a positive response to one of the questions

- Supervision of the step test by a physician in order to prevent any complication

- Voluntary participation in the study and optional withdrawal from the study

- Confidentiality of information about the participants

\subsection{Statistical analysis}

Data analysis were carried out using independent t-test, one way analysis of variance and Pearson correlation in the SPSS software.

\section{Results}

The mean and standard deviation of age, weight, height and body mass index in the participants were $21.69 \pm 4.99$ years, $76.19 \pm 11.23 \mathrm{~kg}, 177.50 \pm 4.88 \mathrm{~cm}, 24.15 \pm 3.18 \mathrm{~kg} / \mathrm{m}^{2}$, respectively. A total of $83.9 \%$ of the participants were single, and 5.4\% were smokers. Mean and standard deviation of exercise hours per week were a reported $4.42 \pm 3.56$ hours. The greatest amount of maximal oxygen consumption in the medical emergency students was an estimated 4.17 liters per minute using the Gerkin test, and the least was 3.36 liters per minute using the Queen's College test. Maximal oxygen consumption in the George and Jackson tests were obtained as 3.64 and 3.63 liters per minute, respectively. The results of the t-test and analysis of variance showed a significant relationship between independent 
variables of weight $(\mathrm{p}<0.05$ for George and Jackson tests and $\mathrm{p}<0.001$ for the Gerkin and Queen's College tests) and height $(p<0.001)$ with dependent variable of maximal oxygen consumption in fours tests. There was a significant relationship between body mass index and Gerkin $(p<0.001)$ and Queen's College $(p<0.05)$ tests. Exercise hours per week also showed a significant relationship with George and Jackson tests $(p<0.05)$. Relationship of other independent variables with the dependent variable of maximal oxygen consumption is presented in Table 1. Statistical test of Pearson correlation showed a significant relationship among four tests of maximal oxygen consumption $(\mathrm{p}<0.001)$. George and Jackson tests showed the greatest correlation of 0.085 (Table 2$)$.

Table 1. The relationship of population characteristics with VO2 max based on Independent sample T-Test or OneWay ANOVA

\begin{tabular}{|l|l|l|l|l|}
\hline \multirow{2}{*}{ Variable } & \multicolumn{4}{|l|}{ Mean maximum oxygen consumption (lit/min) } \\
\cline { 2 - 6 } & Jackson test & George test & Queen's College test & Gerkin test \\
\hline Age $($ Years $)$ & 0.600 & 0.197 & 0.824 & 0.887 \\
\hline Weight $(\mathrm{Kg})$ & 0.042 & 0.043 & $<0.001$ & $<0.001$ \\
\hline Height $(\mathrm{Cm})$ & $<0.001$ & $<0.001$ & $<0.001$ & $<0.001$ \\
\hline BMI $\left(\mathrm{Kg} / \mathrm{m}^{2}\right)$ & 0.063 & 0.146 & 0.030 & $<0.001$ \\
\hline Exercise in week (Hours) & 0.016 & 0.033 & 0.328 & 0.478 \\
\hline Smoking & 0.803 & 0.608 & 0.301 & 0.366 \\
\hline
\end{tabular}

Table 2. Correlation among Gerkin, Queen's College, Jackson, and George tests

\begin{tabular}{|l|l|l|l|l|}
\hline & Gerkin & Queen's College & Jackson & George \\
\hline Gerkin & - & - & - & - \\
\hline Queen's College & 0.66 & - & - & - \\
\hline Jackson & 0.69 & 0.51 & - & - \\
\hline George & 0.67 & 0.55 & 0.85 & - \\
\hline
\end{tabular}

\section{Discussion}

Test of maximal oxygen consumption is the gold standard for measuring cardio-pulmonary fitness. According to the results, the most and least mean of maximal oxygen consumption in medical emergency students was estimated by the Gerkin test and the Queen's College test. The reason for such difference can be explained by affecting parameters such as age, time of testing and body mass index in the Gerkin formula and recovery heart rate in the Queen's College formula. Given oxygen consumption is estimated by four tests, it can be concluded that participants are able to perform heavy and very heavy work (10). Therefore, students were selected appropriately for the career and are able to meet the requirements of an emergency-related job. These findings are consistent with results of studies conducted by Vandermissen et al. (11), Mier et al. (3) on maximal oxygen consumption in firefighters, Heydari et al. (12) and other studies (13-15) in different populations in terms of ability of performing heavy and very heavy work. Findings of this study showed a significant relationship between weight and maximal oxygen consumption which are consistent with studies conducted by Heydari et al. (12), Rafiee Pour et al. (16), Saremi et al. (17), Arghavani et al. (18), Zare Derisi et al. (14) and Choobineh et al. (19). However, it is contradictory to the results of a study conducted by Daneshmandi et al. (20). Results of this study showed a significant relationship between height and maximal oxygen consumption. Findings of studies conducted by Heydari et al. (12), Rafiee Pour et al. (16), Zare Derisi et al. (14) and Choobineh et al. (19) are consistent with results of this study. Findings of studies conducted by Daneshmandi et al. (20), Saremi et al. (17), and Arghvani et al. (18) are contradictory to the results of this study. Gerkin Treadmill and Queen's College tests showed a significant relationship between body mass index and maximal oxygen consumption, which is consistent with findings of studies conducted by Modasir et al. (21), Vandermissen et al. (11), Hosseinabadi et al. (22), Daneshmandi et al. (13), Zare Derisi et al. (14) and Choobineh et al. (19) and in contradictory to results of studies conducted by Arghavani et al. (18), Saremi et al. (17), Ranjbar et al. (23). The reason of differences in weight, height and body mass index in estimating maximal oxygen consumption in this study compared to other studies, can be explained by the difference in the group under investigation and methods used for estimating maximal oxygen consumption. Significance between maximal oxygen consumption and weight, height and body mass index can be explained by increased oxygen absorption in the pulmonary system and transporting more glucose to the muscles through blood flow (12). As weight and height increase, aerobic capacity increases, which is resulted from increasing systems dependent to maximal oxygen consumption (heart, lung, blood volume and skeletal muscles) during exercise. As an individual grows, weight and height increase, and these systems also grow. Significant relationship between exercise per week and maximal 
oxygen consumption obtained from Jackson and George tests is consistent with results of studies conducted by Daneshmandi et al. (20) and contradictory to the results conducted by Rafiee Pour et al. (16), Hosseinabadi et al. (22) and Arghavani et al. (18). The reason for such difference can be explained by the hours, frequency and intensity of exercise per week. The relationship between maximal oxygen consumption and exercise per week can be explained in that people exercise over different durations per week. Studies also showed the role of exercise in improving physiological functions and aerobic capacity $(19,24)$. Findings of this study showed a significant correlation between field tests (Gerkin ad Queen's College) and non-exercise tests (Jackson and George). Findings of studies conducted by Karegar Fard et al. (25), Zwiren et al. (26), Safrit et al. (27), and Plowman et al. (28) approve findings of this study in terms of significance. Given greater correlation between the Gerkin exercise tests and non-exercise Jackson test, with easy application and no requirement for equipment in the Jackson test, this test can be used in the industry and cases in which participants do not cooperate in exercise. The main advantage of this study is to examine correlation of four methods simultaneously in estimating maximal oxygen consumption in medical emergency students. Limitations of this study were conducting the study on students of Qazvin University of Medical Sciences and their age limitations. Therefore, the results cannot be generalized to the wider population or students in other universities or working class.

\section{Conclusions}

In summary, this study showed the greatest amount of maximal oxygen consumption in medical emergency students using the Gerkin test and the greatest correlation between the George and Jackson tests. Also, variables of weight and height influence maximal oxygen consumption. There was a significant positive correlation between tests that have implications. Thus, it is suggested to use non-exercise tests instead of exercise tests in the condition of less access to the equipment. Further research is suggested on assessment of other dimensions of physical fitness in personnel of field work in the future.

\section{Acknowledgments:}

This study is a Master's thesis entitled maximal oxygen consumption in medical emergency and its application for selecting students. The authors appreciate Qazvin University of Medical Sciences for financial support.

\section{Conflict of Interest:}

There is no conflict of interest to be declared.

\section{Authors' contributions:}

All authors contributed to this project and article equally. All authors read and approved the final manuscript.

\section{References:}

1) Daly W, Seegers CA, Rubin DA, Dobridge JD, Hackney AC. Relationship between stress hormones and testosterone with prolonged endurance exercise. Eur J Appl Physiol. 2005; 93(4): 375-80. doi: 10.1007/s00421-004-1223-1. PMID: 15618989.

2) Klaren RE, Horn GP, Fernhall B, Motl RW. Accuracy of the VO2 peak prediction equation in firefighters. J Occup Med Toxicol. 2014; 9(1): 17. doi: 10.1186/1745-6673-9-17. PMID: 24860611, PMCID: PMC4016782.

3) Mier CM, Gibson AL. Evaluation of a treadmill test for predicting the aerobic capacity of firefighters. Occup Med. 2004; 54(6): 373-8. doi: 10.1093/occmed/kqh008. PMID: 15347781.

4) McArdle WD, Katch FI, Pechar GS, Jacobson L, Ruck S. Reliability and interrelationships between maximal oxygen intake, physical work capacity and step-test scores in college women. Med Sci Sports. 1971; 4(4): 182-6. PMID: 4648576.

5) Chatterjee S, Chatterjee P, Bandyopadhyay A. Validity of Queen's College Step Test for estimation of maximum oxygen uptake in female students. Indian J Med Res. 2005; 121(1): 32-5. PMID: 15713976.

6) Pollock ML, Wilmore JH, Fox SSM. Exercise in health and disease: evaluation and prescription for prevention and rehabilitation: Saunders; 1984.

7) Jackson AS, Blair SN, Mahar MT, Wier LT, Ross RM, Stuteville JE. Prediction of functional aerobic capacity without exercise testing. Med Sci Sports Exerc. 1990; 22(6): 863-70. doi: 10.1249/00005768199012000-00021. PMID: 2287267.

8) Kolkhorst FW, Dolgener FA. Nonexercise model fails to predict aerobic capacity in college students with high VO2 peak. Res Q Exerc Sport. 1994; 65(1): 78-83. doi: 10.1080/02701367.1994.10762211. PMID: 8184215 . 
9) George JD, Stone WJ, Burkett L. Non-exercise VO2max estimation for physically active college students. Med Sci Sports Exerc. 1997; 29(3): 415-23. doi: 10.1097/00005768-199703000-00019. PMID: 9139183.

10) Eramaki MA. Body mechanics and design of work stations. 1st ed. Tehran: Omid Majd; 1999.

11) Vandersmissen G, Verhoogen R, Van Cauwenbergh A, Godderis L. Determinants of maximal oxygen uptake (VO2 max) in fire fighter testing. Appl Ergon. 2014; 45(4): 1063-6. doi: 10.1016/j.apergo.2014.01.001. PMID: 24456897.

12) Heydari P, Varmazyar S, Mohammadzadeh E. Factors affecting estimation of the maximum aerobic capacity by treadmill test in students of medical emergencies in Qazvin. J Qazvin Univ Med Sci. 2016; 19 (6): 65-72.

13) Daneshmandi H, Rajaei Fard A, Choobineh A. Data bank of aerobic capacity (VO2-max) in male industrial workers of Shiraz, Iran, based on age. Journal of health system research, 2013; 2013-9: 42-9.

14) Zare Derisi F, Hosseini S, Daneshmandi H, Choobineh A, Mohammadbeigi A. Correlation of Astrand and ACSM Protocols in Estimating the Maximum Aerobic Capacity (Vo2-Max). Journal of Ergonomics. 2014; 1(3): 27-35.

15) Peate W, Lundergan L, Johnson JJ. Fitness Self-Perception and Vo2max in Firefighters. J Occup Environ Med. 2002; 44(6): 546-50. doi: 10.1097/00043764-200206000-00017. PMID: 12085481.

16) Rafieepour A, Farasati F, Kalantari S, Motamedzadeh M, Rafieepour E. Estimation of maximum aerobic capacity and the effect of demographic factors and personal habits on it in students of Hamadan University of Medical. Qom Univ Med Sci J. 2014; 8(3): 33-40.

17) Firoozeh M, Saremi M, Kavousi A, Maleki A. Investigation into Maximal Aerobic Capacity and its Associated Factors in Firefighters. Iran Occupational Health Journal. 2014; 12(3): 15-26.

18) Arghavani F, Teymuri GH, Ebrahimi K, Rahani KH, Javanmardi MK. Estimation of Maximal Aerobic Capacity (VO2-max) and Study of its Associated Factors among Industrial Male Workers in Sanandaj city/Kurdistan Province 2013. Journal of Medical Sciences Torbat. 2014; 2(5): 34-42.

19) Choobineh A, Gholami T, Amiri R, Tabatabaei HR, Almasi Hashyanie A. Estimation of aerobic capacity (Vo2-max) and study of its associated factors among male workers of industrial factories in Sepidan/Fars province, 2009. Jundishapur Scientific Medical Journal. 2011; 10(1): 1-12.

20) Daneshmandi H, Choobineh A, Rajaei Fard A. Estimation of aerobic capacity and determination of its associated factors among male workers of industrial sector of Shiraz city, 2010. Iran Occupational Health. 2011; 8(3): 48-58.

21) Mirza M, Aparna A, Sreemala P. Correlation between Fitness Index and BMI among 1 st MBBS Students of a Tribal District Teaching Hospital of India. J Cont Med A Dent May. 2014; 2(2): 55-8. doi: $10.18049 / \mathrm{jcmad} / 229 \mathrm{a} 11$.

22) Hosseinabadi S, Bagejan PH, Ebrahimi H, Barkhordari A, Bandepe TR. Estimation of Aerobic Capacity (VO2-max) and Physical Work Capacity in Laborers. Knowledge \& Health. 2013; 8(3): 131-7.

23) Ranjbar K, Nourshahi M, Gholamali M. Relationship between Anthropometric Factors, Respiratory Exchange Ratio and Energy Expenditure with Maximal Oxygen Uptake among Sedentary Men. Zahedan Journal of Research in Medical Sciences. 2014; 16(6): 20-4.

24) Airila A, Hakanen J, Punakallio A, Lusa S, Luukkonen R. Is work engagement related to work ability beyond working conditions and lifestyle factors? Int Arch Occup Environ Health. 2012; 85(8): 915-25. doi: 10.1007/s00420-012-0732-1. PMID: 22270385.

25) Karegar Fard M, Asgari B. The relationship between the one-mile run test, Queen step and non-exercise model to estimate maximal oxygen consumption active students. Olympic Journal. 2005; 13(4): 85-97.

26) Zwiren LD, Freedson PS, Ward A, Wilke S, Rippe JM. Estimation of VO2max: a comparative analysis of five exercise tests. Res Q Exerc Sport. 1991; 62(1): 73-8. doi: 10.1080/02701367.1991.10607521. PMID: 2028096.

27) Safrit MJ, Wood TM. Introduction to measurement in physical education and exercise science. William C. Brown; 1995.

28) Dustman-Allen KM, Plowman SA, Looney MA. Validation of a non-exercise regression equation for the prediction of maximal aerobic capacity. Medicine \& Science in Sports \& Exercise. 2003; 35(5): S310. 